Briefly, whilst the two electrode processes $\mathrm{Fe}+$ $2 \theta \rightleftarrows \mathrm{Fe}$ are subject to considerable irreversible effects, which limit the maximum practicable current densities to relatively low figures, this is not the case with the electrode processes $\mathrm{Zn}+2 \theta \rightleftarrows \mathrm{Zn}$. There is no need to emphasise a point known to all. Iron is a metal which becomes passive with notorious ease when used as anode, and the work of Foerster has demonstrated the existence of important retardation effects during its cathodic deposition. Zinc, on the other hand, dissolves freely on anodic polarisation, as in many types of primary cell, and very high current densities are known to be used successfully in its technical electro-deposition. As a result, far heavier currents can be put through a $\mathrm{Zn} / \mathrm{Zn}$ than through a $\mathrm{Fe} / \mathrm{Fe}$ electrode, during both charge and discharge. The properties of the $\mathrm{NiO} / \mathrm{Ni}_{2} \mathrm{O}_{3}$ electrode are sufficiently good from the same point of view with the consequence that the Drumm battery, which combines these two electrode systems, can both be charged and discharged at abnormally high rates. The standard rate of charging of a single technical cell of total weight $112 \mathrm{lb}$., allowing for all losses in efficiency, corresponds to an input of $0 \cdot 134$ effective watthour/lb./minute, about four times the rate normal to other alkaline batteries. In practice, the same cell is normally discharged at a current of 400 amperes and an average voltage of 1.65 volts, equivalent to practically $0 \cdot 1$ watt-hour $/ \mathrm{lb}$./minute. This itself is twice the highest diseharge rate recommended for other alkaline batteries. But, over and above this, the current can, when required, be raised to 1000 amperes for limited periods, corresponding to an energy delivery of about 0.22 watt-hour $/ \mathrm{lb}$. minute-a very high figure indeed. The cell deals with these heavy loads quite comfortably, with no sign of deterioration.

The power of furnishing energy at these unprecedented rates makes it possible for a traction battery of Drumm cells to overcome the grave disadvantage inherent in the majority of such batteries, namely, the impossibility of furnishing rapid accelerations. The train now operating between Dublin and Bray can accelerate from a standstill at about 1 mile per hour per second, attain speeds of 40-50 miles an hour with ease, and is provided with a successful system of regenerative braking, whereby an important fraction of the energy surge made available on a down-gradient or on decelerating at a station is returned to the battery.

There is one further very important matter. The specific watt-hour capacity of the Drumm cell on a single charge is not particularly high. In fact, in the case of the battery especially designed for the above train, it is very low-perhaps 15 per cent of that of an iron battery. But its capacity for high loads enables this battery to be charged at the termini and afterwards discharged many times during the working day; probably twenty such charges will be standard when in full operation. Consequently, the daily work of which unit weight of battery is capable will be, not 15 per cent, but 300 per cent of the normal-a fact naturally of prime importance when considering initial costs, quite apart from the elimination of the expense of an all-night charge.

With regard to other practical points, the cell possesses to a high degree the virtues of simplicity of construction and of operation, whilst there are definite grounds, which I am not at liberty to mention, for anticipating a long life. Neither overcharge, nor overdischarge, nor long idle periods have any ill effect of importance. Self-discharge is exceedingly low.

A few electro-chemical details may be added in conclusion. Under standard working conditions, the average current efficiency is $92-93$ per cent, the concordant result of long-continued tests on cells of varying capacity. The average voltage during charge and discharge is 2.03 and 1.65 respectively. The energy efficiency is therefore practically 75 per cent. These are favourable figures, and strikingly so when it is remembered for what high loads they hold good ; they also connote relatively small gassing and low temperature rise. During the greater part of both charge and discharge periods, the polarisation alters linearly with time. Investigation shows this change to be due almost entirely to the positive plate. The polarisation at the negative is considerably less than at the positive, and scarcely alters with time (unless the cell be overdischarged). Of the total voltage losses in a cycle, roughly half is associated with the positive, and one-quarter each with the negative and the electrolyte. The exact concentrations of caustic potash and of zinc oxide in the latter vary in accordance with the purpose for which the cell is designed, and there is no point in giving detailed figures. The essential points are, of course, an electrolyte of high conductivity and sufficient dissolved zinc oxide for the operating conditions.

It is clear that Dr. Drumm has produced a cell of somewhat remarkable properties, and that, although primarily designed for transport purposes, these properties may lead to its utilisation in other fields.

\title{
Adsorption of Gases
}

THE recent discussion held by the Faraday 1 Society at Oxford, on Jan. 12-13, was devoted to a consideration of the problems connected with the adsorption of gases. The general introduction was given by Prof. H. S. Taylor of Princeton University, and a number of distinguished foreign guests presented their communications in person, including Prof. A. Magnus of Frankfort, Prof. A. F. Benton of Virginia, Prof. E. Huckel of
Stuttgart, Dr. A. Farkas of Frankfort, and Drs. H. Dohse and Schuster of Ludwigshafen. The attention of the meeting was devoted almost exclusively to two important considerations, types of adsorption and discontinuities in adsorption processes.

A study of the chemical behaviour of adsorbed molecules as well as the great difference in the heats of adsorption of gases on substances such as silica.

No. 3254 , VoL. 129] 
and the metals led to an early differentiation between two types of adsorption, one where the adsorbate was relatively lightly attached, with small heats of adsorption, and another type where the heats of adsorption approximate to those involved in chemical linkages. These were early characterised as physical and chemical adsorption respectively. If this is in fact the case, it should be possible to demonstrate the actual existence of these two types of adsorption in the same system, for the physical type which is only loosely held should be operative alone at low temperatures, whilst the other type should occur at higher temperatures, if as in chemical reactions an energy of activation is required. Examples of such dual adsorption processes in the same system were first demonstrated by Benton and later by Nikitin; more recently their number has been extended very considerably by Taylor, by Garner, and by Kingman.

Following the earlier concepts, it has been customary to consider the low temperature adsorption as due to Van der Waals forces, and the one occurring at higher temperatures and requiring an energy of activation as due to chemical forces, that is, due to a change in the character of the union of the metal to adsorbate. An analysis of the problem by Lennard-Jones indicates that this is not necessarily the case, for a diatomic molecule may be regarded as dissociated on activation into atoms on the metal surface, and it is shown that the potential curves for the approach of a molecule and of an atom may cut one another, so that the transition from one form to the other is possible. In the nonactivated adsorption we are dealing with the system $M+X_{2}$, in the activated adsorption with $M+2 X$; the nature of the forces involved in both cases are, however, identical. It is clearly possible that, in addition to non-activated and activated adsorption, chemi-adsorption involving a more fundamental electronic change may occur, for example, $M+X \rightarrow M^{+} X^{1}$, requiring again a different energy of activation. Examples of all three types of adsorption are known, and the evidence for the presence of these three types in one system over a suitably wide range of temperature has been presented by Garner.

Activated adsorption probably cannot involve in all cases the actual separation of the atoms in a diatomic molecule into two independent entities, for example, carbon monoxide on metals; nor can the energies of activated adsorption and of chemiadsorption be always widely different from one another, for it appears probable that oxygen on most metals, and nitrogen on many metals, undergoes chemi-adsorption as readily as or more readily than activated adsorption. It is interesting to note that the activated adsorption of carbon dioxide on iron probably involves the formation of carbon monoxide, which is 'physically' adsorbed, and chemi-adsorbed oxygen. It is also worthy of comment that the linkage of the metal atom holding the adsorbate is weakened by the process of chemi-adsorption, and in many cases on reevaporation the substrate is removed in true chemical combination with the adsorbate.
The nature of the process of activation is as yet not so clearly visualised. Adopting for energies of activation values less than 15,000 calories per gm. molecule, activation cannot result on mere collision of a gas molecule with any portion of the metal surface, since the velocity of the process at low temperatures is too small. Certain portions of the surface appear more susceptible than others. The investigations of London and of Polanyi make it appear probable that the energy of activation is dependent on the lattice spacing or the distance between two metallic atoms in the adsorbent. The energy required for activaton rises rapidly as a certain optimum spacing is departed from either on contraction or expansion.

Over certain ranges of temperature the rate of uptake of gas in the activated adsorbed state is slow. No unanimity of opinion was obtained at Oxford as to the cause of this slow rate of uptake. It is believed by some that this actually represents the rate of activation, and energies of activation have been calculated from the velocities at different temperatures. That the process of surface migration and intergranular diffusion along the secondary structure of the metal crystal on solid surfaces requires an energy of activation for the adsorbate to jump over the potential barriers between the atoms has been experimentally demonstrated in a number of cases, and formed the subject of several communications, including those of Becker for allkali metals, Volmer for mercury and benzophenone, Chariton, Semenoff and Shalnikoff for metals, Ward for activated adsorbed hydrogen on copper, and by the writer for gases. As pointed out by Lennard-Jones and by Fowler, this is in accord with the general theory, energies of activation for migration of adsorbed, activated adsorbed, and chemi-adsorbed molecules being in general necessary and of different magnitudes.

The increase in rate of activated adsorption with the temperature and the energy of activation calculated therefrom must be ascribed either to an increase in the number of doublets formed by thermal agitation of the metal or alternatively to an increased rate of diffusion of the activated adsorbed molecules (in some cases possibly as atoms) away from the doublets. Both factors may indeed be operative over certain ranges of temperature. That activated adsorbed gas can actually leave the seat of activation and migrate over the substrate was evident from the communication of Frumkin and of Egerton and Ubbelhode, and a distinction between the two hypotheses is also possible by an examination of the effects of poisons on the process, as exemplified by the work of Maxted.

Whilst the pressure retention curves both for adsorption and activated adsorption over considerable ranges of pressure and temperatures obey the isotherm of Langmuir, examples of change of state of the adsorbed gas or vapour, as exemplified by the interesting work of Farkas and Bonhoeffer on the para-ortho hydrogen inversion on nickel surfaces, are by no means uncommon, for example,

No. 3254, VoL. 129] 
cæsium on tungsten, examined by Langmuir. Even more remarkable, however, are the minor discontinuities or steps observed by Allmand, Burrage and Chaplin for the adsorption of vapours such as carbon tetrachloride and sulphur dioxide on charcoal and on silica gel, and by Benton and White for hydrogen at low temperatures on metals and nitrogen on copper and iron.

The phenomenon appears to occur with normal adsorption rather than with activated or chemiadsorption, and is ascribed by Benton to prefer- ential adsorption on various selected portions of the substrate, such as the edges and corners of the micro-crystals of the metal.

It is probable that many of the visitors to this large and well-organised meeting came with the idea that only one type of adsorption was certain, but it is almost inconceivable that they left Oxford without being conversant with at least three types of adsorption, the characteristies of which could easily be recognised but the nomenclature of which remained undetermined.

\section{Obituary}

Sir William Somerville, K.B.E., LL.D. LTHOUGH illness led to his retirement from $\mathrm{A}^{\mathrm{L}}$ active work some years ago, the sudden death from pneumonia, on Feb. 17, of Sir William Somerville, emeritus professor of agriculture and rural economy in the University of Oxford, came as a shock to many friends. To the progress made by agricultural education during the past fifty years his contribution was outstanding. Those who knew Somerville only in the committee room or common room, even those who recognised in him a delightful companion in the open air, equally at home in the field and woodland and garden, happy with a gun under his arm, but, above all, content with a rod in his hand and a meerschaum pipe between his lips, must sometimes have asked themselves how it was that among practical farmers his reputation was unrivalled, and why among foresters his opinions on arboricultural questions were so highly valued. Other notices of him have dealt with his later career ; here reference will be made chiefly to his early work in the years when he acquired the experience which made him in later life so valued a counsellor.

Somerville had attended the agricultural class at the University of Edinburgh when John Wilson was professor; but I do not think that he then had any intention of taking up agricultural education as a career. When Robert Wallace moved from Cirencester to succeed Wilson at Edinburgh in 1885, Somerville, attracted by the energy and reputation of the young professor, resumed his interrupted studies; he was class medallist in Wallace's first year, and when he had graduated at Edinburgh and at Munich, I believe it was the influence of Wallace that led him to adopt teaching as a profession. He considered the offer of an appointment in India in 1889 , but for family reasons he then decided not to leave Edinburgh, and being specially interested in forestry, which he had studied in Munich, Somerville began his career as lecturer in forestry in his own University.

In 1891, Somerville went from Edinburgh to Newcastle-upon-Tyne as professor of agriculture and forestry in the Durham College of Science (now Armstrong College). Reference to his work there is made below. In 1899 he was elected Drapers' professor of agriculture at Cambridge. He was the first occupant of this chair, and the two years which he spent in Cambridge were devoted to the organisation of the new department, the provision of a farm for experimental work, and to establishing contact with farmers in the eastern counties. In 1901 he left Cambridge on being appointed an assistant secretary in the Board of Agriculture and Fisheries ; but the multifarious duties which tie an assistant secretary to a Whitehall desk were little to the taste of a man with Somerville's love for the field and woodland, and in 1906, when an opportunity of returning to educational work presented itself, he accepted the Sibthorpian professorship at Oxford, and there the rest of his working life was spent.

When he settled in Oxford, Somerville had two objectives. In his official capacity it was his duty to develop there a course of study suited to the needs of the Oxford student. It was clear that the special circumstances of those likely to inherit land or to undertake estate-management must be kept in view, and to them Somerville was specially fitted to act as friend and guide. But Somerville's ideals were not satisfied by lecturing on principles. $\mathrm{He}$ held it to be his duty to practise as well as to teach ; he therefore acquired and farmed land in two English counties. He had had much experience in experimental work; but here his object was demonstration, not experiment-his farms were run on commercial lines. He knew that he could make farming pay, and he did.

Somerville's concentration on teaching and demonstration in his later years gave rise to an impression that his interests lay chiefly in practical farming, and that by nature he was not an experimenter who loved his work for its own sake. This was not the case. In his early years Somerville was an enthusiastic and indefatigable experimenter. He was not prepared to take statements on trust. His motto, indeed, was 'Prove all things', and he followed up this injunction by holding fast to what he found to be good. In public discussion, once his point of view had been stated he was very difficult to move: he always had facts ready if his views were challenged. But Somerville was by no means dogmatic; he would weigh deliberately points put to him in conversation, and was as ready to agree as to differ. His attitude when his views were challenged in public, those who knew his early work can explain and can justify.

When Somerville went to Newcastle in 1891, his knowledge of the subjects then interesting Scottish farmers and his German training in scientific methods enabled him both to grasp quickly those 